\title{
Research on the Company Financial Crisis Prediction Model based on Support Vector Machine
}

\author{
Weiping Zhong \\ Department of Economics, Qinhuangdao Institute of Technology, Qinhuangdao, 066000, China
}

Keywords: Support vector machine; Financial crisis; Prediction model

\begin{abstract}
For comparing the prediction accuracy of company financial crisis prediction models, the support vector machine model was introduced in this paper to predict that whether there exists financial crisis in a company or not. Through the acquisition of a large number of samples for training and testing, the specific example's results demonstrate that the financial crisis prediction model based on support vector machine can effectively predict the financial crisis. The prediction accuracy of the training samples and testing sample respectively are $94.5 \%$ and $93.9 \%$, which is better than the neural network model.
\end{abstract}

\section{Introduction}

With the further deepening of China's market economic reform and accelerate the integration of the global economy, companies are in a critical period of development, especially in increasing the financial risks that enterprises face[1]. In this competitive environment, how to help companies effectively disperse and avoid financial crisis has became the hot topic in theoretical exploration. The financial crisis prediction system is an important part of company risk management, and is increasingly attracted attention of practitioners[2]. In recent years, the models of statistical analysis, logistic regression analysis, principal component analysis and BP neural network models and other methods has been applied in financial crisis prediction of listed companies. In this paper, support vector machine(SVM) theory was introduced to establish the financial crisis prediction model of listed company aiming to improve the practicality and accuracy of prediction model[3,4].

\section{Support Vector Machine}

SVM is a new learning method based on structural risk minimization principle of the machine, which can make full use of the limited sample learning acquisition decision function with high generalization ability. Considering a two classification models, a training sample is defined as $\left\{\left(x_{i}, y_{i}\right)\right\}$, where $x_{i}$ represents the input vector and $y_{i}$ represents the classification sign. The two classes of linear discriminant function of separable cases are as follows:

$$
f(x)=w \cdot \varphi(x)+b
$$

Where $x$ is the sample vector, $w$ is the weight vector, $b$ represents the classification threshold.This process can be described as Fig 1 . 


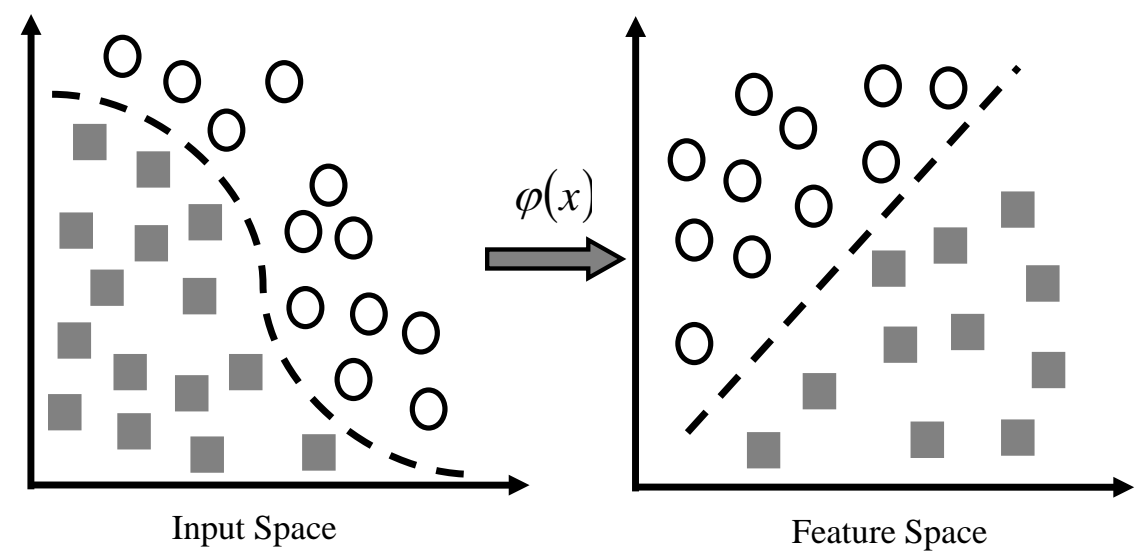

Fig 1: Illustration of the transformation process of SVM model

Supposing there is a classification decision plane:

$$
f(x)=w \cdot \varphi(x)+b=0 \text {. }
$$

Which satisfies:

$$
f(x)= \begin{cases}w \cdot \varphi(x)+b>0 & y_{i}=+1 \\ w \cdot \varphi(x)+b<0 & y_{i}=-1\end{cases}
$$

Thus, Eq.(2) is defined as the classification and ultra flat surface of support vector.

A two types of linear separable linear sample set $\left\{\left(x_{i}, y_{i}\right)\right\}^{N}, i=1,2, \cdots, n$ is given. The weight vector $w$ in hyperplane and classification threshold $b$ are both obtained. As to any support vector $X_{s v}$ and its classification label $y_{s v}$, it satisfies the following condition.

$$
f\left(x_{s v}\right)=W^{T} x_{s v}+b= \begin{cases}+1 & y_{s v}=+1 \\ -1 & y_{s v}=-1\end{cases}
$$

The maximum interval of the classification plane can be calculated as $\frac{2}{\|w\|}$, Therefore, the maximum class interval is equivalent to the minimum. If the surplus plane need to classify all samples correctly, it must satisfy:

$$
y_{i}\left(W^{T} x_{i}+b\right)-1 \geq 0, i=0,1,2, \cdots, N
$$

Thus, the SVM hyperplane by solving the following constrained optimization problem was the solution:

$$
\min _{w} \frac{1}{2} W^{T} W
$$

Which is a A typical quadratic programming problem. The optimal solution is a saddle point of the following Lagrangian:

$$
L(w, b, a)=\frac{1}{2}(w, w)^{T}-\sum_{i=1}^{l} \alpha_{i}\left[\left(x_{i} w-b\right)-1\right]
$$

Where $a_{i}$ is the Lagrange multipliers, The above optimization problem inverts into a dual form to get the solution:

$$
\max W(\alpha)=\min \left(-\frac{1}{2} \sum_{i, j=1}^{n} \alpha_{i} \alpha_{j} y_{i} u_{j} k\left(x_{i}, x_{j}\right)\right) \sum_{i=1}^{n} \alpha_{i}
$$

According KKT conditions, those points on the boundary of two types of sample points fall in support vector machine SVM required solution. Classification decision function is obtained as follows: 


$$
f(x)=\operatorname{sign}\left(\sum_{i, j=1}^{n} \alpha_{i} y_{i} k\left(x_{i}, x_{j}\right)+b\right)
$$

Where $y_{i}$ is category symbol and belongs to $\{+1,-1\} ; a_{i}^{*}$ is an constant and is above zero; $K$ is the mapping function that is generally replaced by kernel function; $b^{*}$ is category field value.

\section{Company financial crisis prediction index system}

This paper regards the listed companies as study samples, and focuses on the introduction of cash flow information which includes the cash ratio and the cash earnings ratio. The financial index information and cash flow information of 90 special treatment (ST) companies and 90 non-ST companies are consider as financial crisis prediction indexes, and the SVM is applied in the prediction model. A combination method of qualitative and quantitative analysis is used to establish the company financial crisis prediction index system. Considering the company short-term liquidity and long-term solvency, profitability, asset management and corporate development capacity, 14 financial indexes construct the prediction index system, which is shown in Table 1.

Table 1. Financial crisis prediction index system

\begin{tabular}{cc}
\hline Financial characteristics & Financial ratios \\
\hline \multirow{3}{*}{ Short-term solvency } & $\mathrm{X}_{1}$ : Current ratio \\
& $\mathrm{X}_{2}$ : Quick ratio \\
& $\mathrm{X}_{3}$ : Cash ratio \\
Long-term solvency & $\mathrm{X}_{4}$ : Equity ratio \\
& $\mathrm{X}_{5}$ : Interest coverage ratio \\
& $\mathrm{X}_{6}$ : Cash earnings ratio \\
Profitability & $\mathrm{X}_{7}$ : Return on total assets \\
& $\mathrm{X}_{8}$ : Return on equity \\
& $\mathrm{X}_{9}$ : Inventory turnover \\
Asset management & $\mathrm{X}_{10}$ : Accounts receivable turnover \\
capabilities & $\mathrm{X}_{11}$ : Total asset turnover \\
& $\mathrm{X}_{12}:$ Increasing the value of assets \\
& $\mathrm{X}_{13}$ : Net profit growth \\
Development capacity & $\mathrm{X}_{14}$ : Cumulative profitability \\
\hline
\end{tabular}

\section{Company financial crisis prediction model based on SVM}

(1) Data Preparation

In the sample selection process, 90 ST companies and 90 non-ST companies in Shenzhen stock market and Shanghai stock market were selected. The sample statistics are shown in Table 2.

Table 2. Sample statistics

\begin{tabular}{cccc}
\hline Stock market & ST & Non-ST & Total \\
\hline Shenzhen & 55 & 50 & 105 \\
Shanghai & 35 & 40 & 75 \\
Total & 90 & 90 & 180 \\
\hline
\end{tabular}

(2) Model training and parameters selection

In the establishment of SVM model, the selection of the appropriate kernel function and regularization parameter $C$ is very important. Their reasonable choice directly affects the accuracy and generalization ability of the model. Through a number of experiments, Radial basis function(RBF) is regarded as the kernel function best, which is expressed as follows: 


$$
K(x, y)=\exp \left(-\frac{\|x-y\|}{2 \sigma^{2}}\right) .
$$

Where $\sigma$ is the kernel parameter.

The web search method was used to determine the regularization parameter $C$ and kernel parameter $\sigma$. Ultimately $C$ takes 300 and $\sigma$ takes 30 .

(3) Specific example calculation and analysis

According to the model testing procedures, the corresponding training samples were put in SVM model. The determination and prediction results of training and testing samples are respectively shown in Table 3 and Table 4. In order to further illustrate the higher predict accuracy of SVM model, this paper applied the BP neural network model in the same financial crisis prediction index system with the same samples.

Table 3. The results of training sample

\begin{tabular}{ccccc}
\hline & \multicolumn{2}{c}{$\begin{array}{c}\text { BP neural network } \\
\text { model }\end{array}$} & \multicolumn{2}{c}{ SVM model } \\
\cline { 2 - 5 } Group & $\begin{array}{c}\text { Actual } \\
\text { number }\end{array}$ & $\begin{array}{c}\text { Correct } \\
\text { classificati } \\
\text { on number }\end{array}$ & $\begin{array}{c}\text { Actual } \\
\text { number }\end{array}$ & $\begin{array}{c}\text { Correct } \\
\text { classification } \\
\text { number }\end{array}$ \\
\hline ST & 60 & 53 & 60 & 59 \\
Non-ST & 60 & 55 & 60 & 56 \\
Correct & \multicolumn{2}{c}{90.2} & & 94.5 \\
rate(\%) & & & & \multicolumn{2}{c}{} \\
\hline
\end{tabular}

Table 4. The results of testing sample

\begin{tabular}{ccccc}
\hline & \multicolumn{2}{c}{$\begin{array}{c}\text { BP neural network } \\
\text { model }\end{array}$} & \multicolumn{2}{c}{ SVM model } \\
\cline { 2 - 5 } Group & $\begin{array}{c}\text { Actual } \\
\text { number }\end{array}$ & $\begin{array}{c}\text { Correct } \\
\text { classificati } \\
\text { on number }\end{array}$ & $\begin{array}{c}\text { Actual } \\
\text { number }\end{array}$ & $\begin{array}{c}\text { Correct } \\
\text { classification } \\
\text { number }\end{array}$ \\
\hline ST & 30 & 25 & 30 & 28 \\
Non-ST & 30 & 27 & 30 & 28 \\
Correct & \multicolumn{2}{c}{89.1} & & 93.9 \\
rate(\%) & & & & \\
\hline
\end{tabular}

By comparing the results of the two models, the determination accuracy of two models are both quite good. In contrast, SVM determines a higher accuracy rate overall. Moreover, the discriminant rate of the two models for testing sample are respectively lower than those of training samples. But with respect to the proposed model, the correct determination rate of in BP neural network declines faster, which can demonstrate that the SVM model has higher prediction accuracy and better generalization ability.

\section{Conclusion}

The specific example results conclude that SVM is an effective model to predict whether company financial crises will occur, and its prediction accuracy rate is higher than BP neural network model. Therefore, the SVM model can replace the BP neural network model to establish the financial crisis prediction model. The reason why SVM is superior to BP neural network can be attributed to: (1) SVM depends only on the support vector that is generally less than the number of samples, which can effectively reduce the complexity of modeling; (2) SVM model minimized the structure risk of a theoretical model, which can improve the generalization ability of the model; (3) Compared with neural networks, SVM does not need to determine the number of nodes in the hidden layer. After SVM determined the input node, the connection weights are determined by the 
optimum algorithm. In contrast, the neural network used the gradient descent method, the results obtained are easily affected by local extreme value, and the initial value of the network connection is empirically selected.

SVM has great practical value in effectively predicting whether company financial crisis will occur. The selection method of parameters and the selection of kernel function are still an important exploration topic, which can model and predict better company financial.

\section{References}

[1] Ruibin Geng, Indranil Bose, Xi Chen. Prediction of financial distress: An empirical study of listed Chinese companies using data mining. European Journal of Operational Research. 241(1), Issue 1, pp. 236-247, 2015.

[2] Angela Hausman, Wesley J. Johnston. The role of innovation in driving the economy: Lessons from the global financial crisis. Journal of Business Research. 67(1), pp. 2720-2726, 2014.

[3] WEN Fenghua, XIAO Jihong, HE Zhifang, GONG Xu. Stock Price Prediction based on SSA and SVM. Procedia Computer Science. 31, pp. 625-631, 2014.

[4] Benlan He, Yong Shi, Qian Wan, Xi Zhao. Prediction of Customer Attrition of Commercial Banks based on SVM Model. Procedia Computer Science, 31, pp. 423-430, 2014.

[5] Limeng Cui, Yong Shi. A Method based on One-class SVM for News Recommendation. Procedia Computer Science,31. (11), pp. 281-290,2014.

[6] Benlan He, Yong Shi, Qian Wan, Xi Zhao. Prediction of Customer Attrition of Commercial Banks based on SVM Model. Procedia Computer Science, 31 (18), pp. 423-430,2014.

[7] Jan Chorowski, Jian Wang, Jacek M. Zurada. Review and performance comparison of SVMand ELM-based classifiers. Neurocomputing,128 (8), pp. 507-516,2014.

[8] Liu Jian, Tan Tianyuan. LS-SVM based substation circuit breakers maintenance scheduling optimization. International Journal of Electrical Power \& Energy Systems. 64, pp. 1251-1258, 2015.

[9] Benlan He, Yong Shi, Qian Wan, Xi Zhao. Prediction of Customer Attrition of Commercial Banks based on SVM Model. Procedia Computer Science. 31, pp. 423-430, 2014.

[10] Limeng Cui, Yong Shi. A Method based on One-class SVM for News Recommendation. Procedia Computer Science. 31, pp. 281-290, 2014. 